\title{
Role of sphincterotomy in extracapsular cataract surgery
}

\author{
M D COLE, R BROWN, AND A E A RIDGWAY \\ From Manchester Royal Eye Hospital
}

SUMMARY Forty patients subjected to extracapsular cataract extraction with posterior chamber intraocular lens implantation in whom a sphincterotomy was required are reported on. This method was used to counter the problems created by a small pupil during surgery. The technique is described and results evaluated.

Extracapsular cataract surgery with posterior chamber intraocular lens implantation has gained widespread popularity over the last 10 years. However, there is reluctance to perform this procedure in eyes known to have poor dilatation of the pupil because of the potential for increased surgical problems. We describe techniques using a peripheral iridectomy extended to form a sphincterotomy, designed to overcome the technical difficulties. We evaluate the results of 40 operations and review the literature.

\section{Material and methods}

We tried to dilate the pupils preoperatively with 2 drops of phenylephrine $10 \%$ and 4 drops of cyclopentolate $1 \%$ at 10 -minute intervals starting one hour before surgery. Eleven patients received general and 29 local anaesthesia. The latter consisted of a retrobulbar injection of a mixture of $2 \mathrm{ml} 2 \%$ lignocaine and $2 \mathrm{ml} 0.5 \%$ bupivacaine with $1 / 200000$ adrenaline in which was dissolved $1500 \mathrm{IU}$ hyaluronidase, followed by 10 minutes of gentle manual bulbar compression. A Pierse wire speculum was inserted. A superior rectus fixation was used only when exposure of the superior limbus was inadequate. A reverse slope corneal section down to Descemet's membrane was made from 10 to 2 o'clock at the apex of the limbal arcade of vessels with a diamond knife, skirting anterior to any drainage bleb present.

As will be seen, the procedure used varied at this point. In the main group of patients ( $B$, below) a puncture was made in the section at 12 o'clock, large enough for the entry of a Steriseal cystotome which

Correspondence to Mr A E A Ridgway, FRCS, Manchester Royal Eye Hospital, Oxford Road, Manchester M13 9WH. was attached to a bottle of balanced salt solution (BSS) and used to make an inferior half beer-can anterior capsulotomy. The wound was opened and a small peripheral iridectomy was performed at 12 o'clock. Sphincterotomy was achieved with straight Vannas scissors through the apex of the iridectomy. The sphincterotomy pillars could be swept aside or incarcerated in the wound to allow good exposure of the superior half of the anterior capsule. Healon (Na hyaluronate) was used during this manoeuvre when required to maintain a deep anterior chamber. The superior half of the capsulotomy was then completed, ensuring an opening of adequate size. The nucleus was expressed with an irrigating vectis, and soft lens matter aspirated, the anterior chamber depth being maintained by irrigation from a bottle of BSS via a Steriseal straight coaxial cannula. We aimed to clear all the posterior cortex and leave a clean posterior capsule. Air and/or hyaluronidase was then instilled, the Rayner Y loop offset lens inserted and dialled $90^{\circ}$, and the wound was closed with four or five interrupted 10/0 nylon (Ethicon) sutures. 1):

The patients reviewed fell into three groups (Table

Group $A$. The capsulotomy was carried out through a small pupil, and sphincterotomy was

Table 1 Surgical procedure

\begin{tabular}{|c|c|c|c|c|}
\hline & $\begin{array}{l}\text { No. of } \\
\text { eyes }\end{array}$ & $\begin{array}{l}\text { Technical } \\
\text { success }\end{array}$ & $\begin{array}{l}\text { IOL } \\
\text { implanted }\end{array}$ & Complications \\
\hline Group A & 11 & 8 & 7 & $\begin{array}{l}2 \text { Completed } \\
1 \text { Vitreous loss }\end{array}$ \\
\hline Group B & 19 & 18 & 17 & 1 Vitreous loss \\
\hline Group C & 10 & 10 & 10 & - \\
\hline
\end{tabular}


carried out after a difficulty was encountered during expression of the nucleus.

Group B. In patients whose pupils were rigid and undilatable because of synechiae or miotic effects the sphincterotomy was carried out before completion of the capsulotomy.

Group $C$. A final group underwent division of the sphincter because the pupil came down during the manipulation of the cataract, usually during aspiration of cortex.

\section{Results}

Forty of 495 consecutive patients submitted to extracapsular cataract extraction for posterior chamber intraocular lens implantation underwent sphincterotomy (Fig. 1).

Group $A$ (11 eyes). In two eyes the lens was expressed completely, leaving no posterior capsule, and in one eye vitreous followed the nucleus by herniation through a tear in the posterior capsule. The method was successful in seven eyes, though one required a second procedure to implant the lens because it had been wrongly thought that the posterior capsule had been breached at the time of extraction. One eye was not implanted because the anterior chamber depth could not be maintained. This eye subsequently required further aspiration of residual lens cortex. All these operations were technically difficult and the method was abandoned.

Group $B$ (19 eyes). No difficulties were encountered during capsulotomy and nucleus expression, though one eye lost vitreous through a tear in the posterior capsule during aspiration of the cortex, and one eye was not implanted because of difficulty in maintaining the anterior chamber depth. One eye in this group presenting with a contusion cataract had a

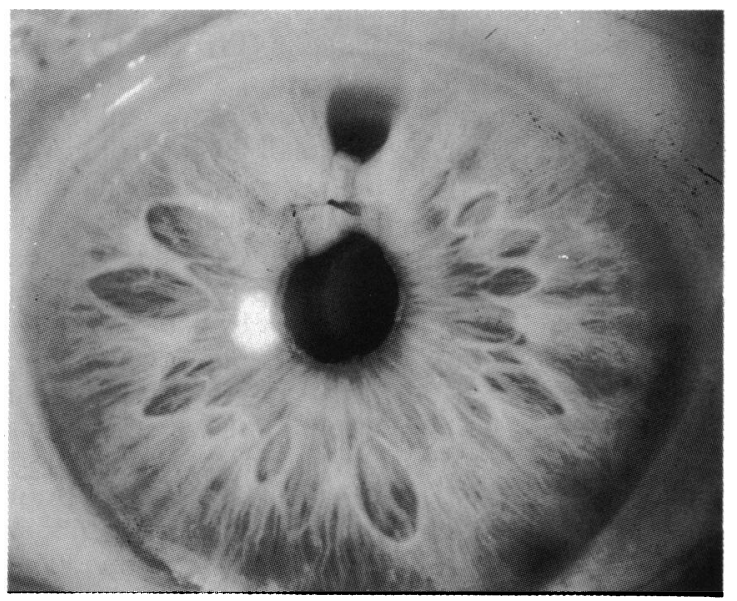

Fig. 1 A sutured sphincterotomy. dense anterior capsular plaque which could not be pierced with a cystotome, and the anterior capsulectomy was carried out with microscissors after sphincterotomy to improve exposure. In two patients the sphincterotomy was performed first, after opening of the wound, and the capsulotomy was carried out under hyaluronate.

Group $C$ (10 eyes). All these operations were technically successful. See Table 1.

Except for eyes which were not implanted 22 sphincterotomies were closed by a single $10 / 0$ nylon tie and 12 were left open. Four eyes of the unsutured group and two of the sutured group produced adhesions between the iris pillars and the free edge of the remaining anterior lens capsule. Such adhesions were usually seen in association with displacement of the intraocular lens. Only one eye, with an unsutured sphincterotomy, developed a localised sector of entrapment without persistent inflammation soon after surgery; 22 months later this had not progressed. Three eyes with resutured sphincters developed updrawn pupils because of misplaced iris sutures. This exposed a dialling hole in one, as did leaving the sphincter unsutured in two others. Two of the three patients affected experienced a ghost image to one side, but neither was concerned by this.

\section{POSTOPERATIVE COMPLICATIONS}

Glaucoma. Patients without preoperative glaucoma had no significant postoperative ocular hypertension. Among the 17 patients who had glaucoma before the operation, postoperative control, defined as intraocular pressures less than $22 \mathrm{mmHg}$ on the same or less medication as before operation, was as good or better in 12 patients and worse in two apart from those not implanted. Both patients whose control worsened had angle closure glaucoma requiring topical medication preoperatively, and both had undergone previous peripheral iridectomy.

Uveitis. A fibrinous exudative uveitis was often seen during the first $\mathbf{4 8}$ hours after operation. This settled rapidly on topical steroid drops in all but three

Table 2 Visual outcome

\begin{tabular}{llll}
\hline Acuity & Group A & Group B & Group C \\
\hline $6-5-6 / 9$ & 6 & 9 & 8 \\
$6 / 12-6-18$ & $3^{*}$ & $5^{*} \S \|$ & $2^{*}$ \\
$<6 / 18$ & $2 \dagger \ddagger$ & $5 \dagger\left(3 \ddagger^{* *}\right)$ & \\
\hline
\end{tabular}

Additional pathology:

*Senile macular degeneration.

†Disciform maculopathy.

¥Advanced glaucoma.

\$Amblyopia.

Congenital nystagmus.

ๆBranch retinal vein occlusion.

${ }^{* *}$ Corneal scarring. 
eyes, which had postoperative uveitis for longer than six weeks. One case, lasting three months, had a past history of uveitis. One case of uveitis lasted six months without obvious cause, and one patient still has uveitis after 10 weeks, associated with residual lens cortex in the pupillary area.

During follow-up of 1.5-22 months no instance of retinal detachment, endophthalmitis, cystoid macular oedema, or corneal decompensation has occurred. The visual outcome is presented in Table 2, together with reasons for unsatisfactory results.

\section{Discussion}

Broad iridectomy is a time honoured aid to extracapsular surgery in eyes where the pupil cannot be dilated.' We present our experience of a group of patients with this problem in whom we wished to implant a posterior chamber intraocular lens. Unlike broad iridectomy, our technique involves the excision of a small peripheral iridectomy alone, with no loss of iris sphincter as has been advocated previously, ${ }^{2}$ and our results show it to be a safe method.

A small pupil may be encountered for a number of reasons (Table 3). Most commonly it is due to synechiae from past glaucoma surgery or uveitis. Though greater dilatation may be achieved by release of synechiae at surgery allowing preoperative mydriasis to take effect, this is often insufficient and usually short lived because of the iris irritation inevitable in their breakdown. Hyaluronate can be used to widen a pupil mechanically during capsulotomy, but the mydriasis may not be maintained once the section is opened. Long-standing miotic therapy is another major factor in poor preoperative dilatation. Altering the regimen to avoid miotics for several weeks prior to surgery may help, but patients on long term pilocarpine are likely to have sphincter hypertrophy and even posterior synechiae, and they may remain unresponsive to mydriasis. Seventeen of $40(42.5 \%)$ patients with glaucoma submitted to intraocular lens implantation required a sphincterotomy. Patients noted to have exfoliation of the lens

\section{Table 3 Cause of poor dilatation}

\footnotetext{
Posterior synaechiae

Previous peripheral iridectomy (1 diabetic)

Previous drainage surgery

Past uveitis

Argyll Robertson pupil

Open angle glaucoma: long-term therapy (1 diabetic)

Pseudoexfoliation syndrome (1 diabetic)

Diabetic iridopathy

Poorly maintained mydriasis

(1 diabetic, 1 uveitis, 2 insufficient drops)
}

capsule, even without raised intraocular pressure or glaucoma, often required a sphincterotomy. Diabetics also required a sphincterotomy more frequently than others, for five of $11(45.5 \%)$ such patients underwent the procedure.

Patients with glaucoma or a past history of uveitis presented only minor additional technical difficulty, though some of the glaucoma patients required prolonged aspiration of copious cortex and often developed a marked fibrinous reaction for the first two postoperative days which responded readily to topical steroid treatment.

Induction and maintenance of a dilated pupil is usually achieved by a combination of sympathomimetic and anticholinergic agents. Recent studies have shown that miosis induced by surgery is due to a number of factors, including trigeminal nerve stimulation, prostaglandin release from the iris, and release of substance $P$ from sensory nerve endings within the eye. ${ }^{3}$ Both topical and systemic prostaglandin inhibitors as well as topical local anaesthetics administered before surgery have been advocated in order to help maintain pupil dilatation. ${ }^{46}$ Substance $\mathrm{P}$ inhibitors may have a role in the future. ${ }^{3}$

Maintenance of a dilated pupil during surgery can be helped by minimising manipulation of the iris and by intracameral administration of dilute epinephrine as a direct injection or in the irrigating solution..$^{78}$ Use of viscous intracameral solutions may also help, as may peroperative injection of subconjunctival Mydricaine Formula 2 (atropine sulphate $1 \mathrm{mg}$, procaine $\mathrm{HU} 6 \mathrm{mg}$, adrenaline solution $0.12 \mathrm{ml}$ ).

Despite these pharmacological and mechanical manoeuvres to induce continued mydriasis, there are a number of eyes in which the problem remains. Surgeons using phacoemulsification may still be able to complete their extraction through a semidilated pupil, but even this technique is difficult through pupil less than $4 \mathrm{~mm}$ in diameter. Praeger improves visualisation by using an angled iris retractor, ${ }^{2}$ but with a nuclear cataract he advocates a small sector iridotomy. Peterson found a small sphincterotomy to achieve a $4 \mathrm{~mm}$ pupil before phacoemulsification useful, and advised against a full sphincterotomy for fear of iris pillar synechiae and subsequent pupil entrapment. ${ }^{2}$ Hoffer has found it possible to perform a formal extracapsular extraction by gently massaging the nucleus through a miotic pupil, which then remains fixed at $6-7 \mathrm{~mm}$ because of the multiple sphincter ruptures produced, ${ }^{2}$ but we found this hazardous. Welch has performed small sphincterotomies at $12,4.30$, and 7.30 o'clock positions prior to capsulotomy. He has also proposed a trapdoor capsulotomy which is swept through the wound and secured to the sclera to retract the superior iris. ${ }^{2}$ 
However, this may risk extension of the capsular tear into the zonule with subsequent vitreous loss. Kokoris has used a collar button iris retractor with infusion during the anterior capsulotomy and maintains the anterior chamber with hyaluronidase. ${ }^{2}$ Simcoe has advocated expression of the nucleus in eyes with small pupils by the use of a small loop made from a 1-inch $(2 \cdot 5-\mathrm{cm}) 25$-gauge blunted needle placed on a tuberculin syringe. Removal of cortex is then facilitated by retracting iris, either with forceps or a blunt hook, temporarily encarcerating the iris in the wound, or by using retraction sutures. ${ }^{9}$

We began by making a sphincterotomy after the capsulotomy in eyes in which a small pupil had made expression of the nucleus difficult, but experienced an unacceptable complication rate. Therefore we consider early sphincterotomy preferable to provide an adequate capsulotomy fashioned under direct vision. Vectis expression then becomes straightforward and tears in the remaining capsule unlikely. Aspiration of cortex is greatly helped by the increased exposure provided. This is especially important in that eyes requiring sphincterotomy often undergo prolonged aspiration for removal of tenacious cortex.

The sphincterotomy may be sutured after insertion of the intraocular lens. This is cosmetically satisfactory, allows near normal iris function, and keeps the iris taut in front of the lens plane, reducing the risk of posterior synechiae and subsequent pupil entrapment. However, our results were similar in both the sutured and unsutured groups. Only one eye with an open sphincterotomy developed synechiae between the pupil margin and the capsule. Even this did not progress to form entrapment after 22 months of follow-up. The risk of entrapment can be minimised by repositioning the iris pillars in front of the intraocular lens after dialling is complete, for iris pillar synechiae did not cause problems, and no progression was seen. More recently sphincterotomy has been used purely to facilitate aspiration of cortex when the pupil constricts excessively during surgery. Complications often arise under these circumstances because the aspiration becomes a blind procedure. Improved visualisation reduces the risk of surgical problems, and our results have been technically successful in all eyes so treated.

\section{CONCLUSION}

Sphincterotomy is a safe aid to extracapsular cataract surgery, providing increased exposure during critical manoeuvres within the eye. It allows for an adequate anterior capsulotomy, enabling easier nucleus expression and complete aspiration of lens cortex. Posterior chamber intraocular lenses can be inserted safely, and they remain stable with or without closure of the sphincter. The procedure may also be employed to facilitate aspiration of lens cortex should the pupil constrict during operation.

The authors thank Mr A B Tullo and Mr M Tutton for constructive criticism of this paper, and Mr I Bradley for photography.

\section{References}

1 Roper-Hall MJ, ed. Stallard's eye surgery. 6th ed. Bristol: Wright, 1980: 558.

2 Shepherd DD. Consultation section: How do you handle a small undilatable pupil for extracapsular cataract extraction with intraocular lens insertion? Am Intraocular Implant Soc J 1983; 9: 60-5.

3 Duffin RM, Camras CB, Gardner SK, Pettit TH. Inhibitors of surgically induced miosis. Ophthalmology (Rochester) 1982; 89: 966-79.

4 Keulen-de-Vos HCJ, Van-Rij G, Renardel de Lavalette JCG. Effect of indomethacin in preventing surgically induced misis. $\mathrm{BrJ}$ Ophthalmol 1983; 67: 94-6.

5 Van-Rij G, Renardel de Lavalette JCG, Baarsma GS, Janson JTG. Effect of oxybuprocaine $0.4 \%$ in preventing surgically induced miosis. Br J Ophthalmol 1984; 68: 248-51.

6 Zimmerman TJ, Gravenstein N, Sugar A, Kaufman H. Aspirin stabilisation of the blood aqueous barrier in the human eye. Am J Ophthalmol 1975; 79: 817-9.

7 Duffin RM, Pettit TH, Straatsma BR. Maintenance of mydriasis with epinephrine during cataract surgery. Ophthalmic Surg 1981; 14: 41-5.

8 Freeman JM, Gettelfinger TC. Maintaining pupillary dilatation during lens implant surgery. Am Intraocular Implant Soc J 1981; 17: $172-3$.

9 Simcoe CW. Small pupil nucleus and cortex removal. Am Intraocular Implant Soc J 1982; 8: 162-3.

Accepted for publication 13 December 1985 